\title{
The Impact of the New Reform Situation on the Optimization of the Organizational System of State- owned Power Enterprises
}

\author{
Han Wang ${ }^{1, *}$, Jinchang Qi $^{2}$, Jian Zhao ${ }^{1}$ \\ ${ }^{1}$ State Grid Energy Research Institute Co.,Ltd., Beijing, 102209, China \\ ${ }^{2}$ State Grid Corporation of China, Beijing, 100031, China \\ * Corresponding author's e-mail: wanghan@sgeri.sgcc.com.cn
}

\begin{abstract}
State-owned state-owned enterprises reform and power system reform are two major reforms currently facing stateowned power enterprises. With the deepening of reforms, the external situation faced by state-owned power companies has become more and more complicated. As an important management foundation of an enterprise, the company's organizational structure is bound to adapt to the development of reforms. This article conducts an in-depth analysis of the current reform situation facing state-owned power enterprises and their impact on the optimization of the company's organizational structure. It explains the impact of the reform situation on the adjustment of the organizational structure of state-owned power enterprises and the future development direction. This article can provide reference for related research.
\end{abstract}

Keywords: State-owned Power Enterprise, Organizational Change, Reform Situation.

\section{INTRODUCTION}

State-owned power enterprises are facing the pressure of both reforms of state-owned assets and state-owned enterprises and reform of the power system.

Since the 18th National Congress of the Communist Party of China, the State-owned Assets Supervision and Administration Commission of the State Council has steadily promoted the " $1+\mathrm{N}$ " policy of state-owned enterprise reform. It has achieved a series of major progress and achieved a series of important results in important areas and key links of state-owned enterprise reform. In June 2020, the "Three-year Action Plan for State-owned Enterprise Reform (2020-2022)" was reviewed and approved, which provided specific construction drawings for state-owned enterprises to further implement the " $1+\mathrm{N}$ " policy system and top-level design.

In 2015, the "Circular 9" and supporting documents of the electricity reform were issued successively, and the new electricity reform officially kicked off. In the following few years, relevant national government ministries and commissions respectively issued a large number of documents on transmission and distribution price reforms, power market construction, incremental power distribution business reforms, distributed power generation market transactions, medium and long-term power trading mechanisms, etc., effectively promoting Reform and innovation of the power system and mechanism. During the "14th Five-Year Plan" period, the reform of the electric power system will go further to provide assistance to accelerate the energy transition process.

Under the above reform situation, the organizational structure of power enterprises must be adjusted and optimized accordingly.

\section{THE IMPACT OF THE REFORM OF STATE-OWNED ASSETS AND STATE- OWNED ENTERPRISES}

\subsection{Change the Function Positioning of the Internal Organization}

On September 27, 2020, the fourth meeting of the State-owned Enterprise Reform Leading Group of the State Council and a video and telephone conference on the mobilization and deployment of the national stateowned enterprise reform three-year action were held. The meeting proposed, state-owned enterprises must become 
market players with core competitiveness, play a greater role in leading innovation, play a leading role in improving the level of the industrial chain and supply chain, play a special role in protecting the livelihood of the society and the people and responding to major challenges, and play a fundamental role in maintaining national economic security, which comprehensively expounds the requirements for state-owned enterprises to play various roles.

This means that in the coming period of time, stateowned power enterprises must pay attention to the responsibilities and roles of central enterprises in all aspects and from multiple angles, and fully implement the company's important roles in politics, economy, and society. State-owned power enterprises should not only pay attention to their own growth, but also the market competition they should face as enterprises, and more importantly, they should pay attention to the leading and guaranteeing role of central enterprises for the overall healthy development of the country and the industry.

In order to ensure that state-owned electric power enterprises can effectively perform their responsibilities in supporting national economic development, ensuring energy security, and maintaining society and people's livelihood, the company's internal organizational structure and departmental responsibilities must be adjusted accordingly to ensure that the organizational function positioning and company responsibility positioning can maintain a high degree of consistency to meet the needs of the reform of state-owned assets and state-owned enterprises, so that the company can play a key role in related important areas.[1]

\subsection{Further Improve the Governance Structure}

On September 29, 2020, the State-owned Assets Supervision and Administration Commission of the State Council held a video conference on the deployment of the three-year action for the reform of central enterprises to mobilize and deploy the three-year action for the reform of central enterprises. The central enterprises are required to adhere to problem-oriented, goal-oriented, and resultoriented, focus on the key tasks of reform, with stronger determination, firmer will, and greater intensity to promote the implementation of results, and set an example in the implementation of the three-year action of state-owned enterprise reform. The central enterprises must do a good job in seven areas: to focus on the construction of a modern enterprise system with Chinese characteristics, to focus on the optimization and structural adjustment of the state-owned economy, deepening the reform of mixed ownership, improving the market-oriented operation mechanism, accelerating the formation of a state-owned asset supervision system based on capital management, the "Double Hundred Action" "Regional Comprehensive Reform Experiment"
"Science Reform Demonstration Action" and world-class enterprises, Party leadership and Party building.

The key tasks of the above reforms are mainly the higher requirements that the management of the company puts forward in the face of state-owned power companies. It is required that the operation and management model of state-owned power enterprises not only adapt to the laws and needs of market-oriented development, but also meet the management and development requirements of state-owned enterprises. State-owned power companies are required to adhere to the party's leadership and also comply with corporate governance norms and standards.[2]

Therefore, state-owned power companies need to further strengthen and improve their governance structure and promote the integration of party leadership into corporate governance. It is necessary to firmly put the Party's leadership in the first place, clarify the power and responsibility boundaries of the Party committee (Party group), the board of directors, and the management team. At the same time, strengthen the board of directors so that the board can effectively and effectively play its role. So as to ensure that the company's party committee, board of directors, and management can take their respective responsibilities, coordinate operations, and effectively check and balance.

\subsection{Improve the Level of Lean Management}

In October 2020, the Fifth Plenary Session of the 19th Central Committee of the Communist Party of China reviewed and approved the "Recommendations of the Central Committee of the Communist Party of China on Formulating the Fourteenth Five-Year Plan for National Economic and Social Development and Long-Term Goals for 2035." The "Proposal" puts forward the main objectives of economic and social development during the "14th Five-Year Plan" period in terms of economic development, reform and opening up, social and ecological civilization construction, people's livelihood and welfare, and national governance. Among them, the promotion of technological innovation and development, strengthening the construction of energy infrastructure, improving the level of digital intelligence, accelerating the implementation of rural modernization, and promoting green and low-carbon development have pointed out the direction and path for the development of state-owned power enterprises during the "14th FiveYear Plan" period. These contents not only provide favorable policies for the innovation and development of state-owned power enterprises in related aspects, but also put forward higher requirements for the transformation of state-owned power enterprises' governance and management models.

On the one hand, state-owned power enterprises should adjust the main functions and scope of 
responsibilities of relevant departments such as technological innovation, power grid construction, rural power grid management, and new energy business, and appropriately add new responsibilities to meet new development needs and business focus. change.[3] On the other hand, business processes within the organization also need to be adjusted accordingly. The development requirements that state-owned power companies face during the "14th Five-Year Plan" period are mostly comprehensive goals. During the implementation, they need to further refine the goals and work together in multiple professional fields to achieve them. Therefore, the internal business of the enterprise The process and the coordination mechanism between various organizations are particularly important.[4]

In general, in order to further promote the implementation of the national "14th Five-Year Plan" at the enterprise level, the organizational structure, organizational functions, business processes, and job responsibilities of state-owned power companies need to be optimized and adjusted.

\section{IMPACT OF POWER SYSTEM REFORM}

\subsection{Further Enrich Organizational Functions}

At present, global energy is undergoing a clean, lowcarbon, and diversified transition. Countries in the world continue to make efforts in the application of clean energy, and constantly adjust the ratio of renewable energy to traditional energy. In the national "14th Five-Year Plan", "promoting green development and promoting the harmonious coexistence of man and nature" is listed as one of the important goals.

As an important means that can effectively promote the large-scale grid integration and market entry of clean energy, the power system reform during the "14th FiveYear Plan" period will help increase the application of clean energy as an important reform task. The implementation of an electricity-centric energy transformation requires the development of integrated energy services on the power supply side, so that clean energy can be packaged into the market with other energy sources, and the proportion of clean energy in it is gradually increased.

Therefore, the responsibility of the power supply company will no longer be to simply supply electric energy and provide power supply services, but may increase important businesses such as integrated energy services, distributed energy, and urban smart energy. For example, the power marketing business may add responsibilities related to integrated energy services, the regulation center business may add responsibilities related to distributed and microgrid regulation, and the distribution network management business may add responsibilities related to the formulation of integrated energy systems and multi-energy complementary strategies. As a result, not only will the functions of the relevant departments undergo certain changes, but the coordination relationships and business processes between the departments will also be adjusted accordingly, and the company's organizational structure will inevitably change.[5]

\subsection{Further Improve Organizational Efficiency}

Before the power transmission and distribution price reform, the income of state-owned power supply companies mainly came from the difference between the electricity sales and the sales price. After the implementation of the power transmission and distribution price reform, the power transmission and distribution price was changed to be determined by the government based on the principle of "permitted costs plus reasonable income" by voltage levels, and users or power sellers pay according to the transmission and distribution price corresponding to the grid voltage level they are connected to. This will be lower than the purchase price difference before the transmission and distribution price reform.

In addition, in the newly revised "Provincial Grid Transmission and Distribution Price Pricing Method" in January 2020, efficiency indicators are set to control new investment, improve allowable rate of return indicators, strictly identify effective assets that can be withdrawn, and reduce working capital and so on, further strengthened the cost constraints on state-owned power supply companies. Moreover, the "Provincial Grid Transmission and Distribution Price Pricing Method" clearly stipulates that the total of the three items of material cost, repair cost and labor cost shall be no more than $2 \%$ of the original value of the new transmission and distribution fixed assets in the supervision period. This requires state-owned power supply companies to further improve efficiency and reduce costs in various ways to ensure that the company's profit margins are not lost.

In an increasingly stimulating market competition environment, the faster an organization responds to market changes and customer needs, the easier it is to get ahead in market competition and win opportunities. Therefore, in order to ensure that state-owned power supply enterprises can still maintain their original market position under the severe situation of the new power reform, it is imperative to improve organizational efficiency. This requires state-owned power supply companies to further optimize their organizational structure, reduce organizational levels, and improve power distribution and decision-making modes by building flat organizations with fewer levels and shorter paths. So as to improve the decision-making efficiency and communication efficiency of the enterprise, and further improve the business process, in order to achieve the purpose of improving organizational efficiency. 


\subsection{Further Adjust the Organizational Model}

The new regulatory model of "liberating the two ends and controlling the middle" requires "orderly liberalize electricity prices for competitive links other than transmission and distribution, orderly open the distribution and sale of electricity to social capital, and orderly liberalize power generation and use plans other than public welfare and regulation; promote relatively independent trading institutions and standardize operations". With the deepening of the new power reform, the market access mechanism on the power generation side and the power sales side has become more open and flexible, and the market structure of buying more and selling is gradually taking shape.

Electricity sales companies have sprung up everywhere, and the original monopoly of state-owned power supply companies in the field of electricity sales has been broken. The state-owned power supply company's original business model of relying solely on electricity sales to obtain profits has been greatly impacted. It is necessary to further expand the company's service areas, develop new market-oriented businesses, and find new profit growth points for the company. In order to meet the needs of business transformation and market changes, the state-owned power supply company needs to adjust the original organizational model. For example, try to build a platform-based organization model in some emerging business areas, transform the company from a pure service provider to a platform that provides resource support, so that the company can more flexibly respond to market changes and the individual needs of customers.

Therefore, state-owned power companies need to establish an open sharing mechanism and empowerment mechanism to create a more flexible organizational model in accordance with changes in business needs and business nature, and promote the overall creation of value around customer needs.

\section{CONCLUSION}

The reform of state-owned assets and state-owned enterprises and the reform of the power system have greatly affected the operation and management models of state-owned power enterprises. As an important foundation of business management, the organizational system is bound to be adjusted with changes in the business management model. Facing the new situation of reform, the organizational structure of state-owned power enterprises should be further streamlined, the organizational structure should be further flattened, and the institutional functions should be further optimized.

\section{ACKNOWLEDGMENT}

This project is supported by the State Grid Corporation of China Technology Project "Research and
Application of Operational Effectiveness Evaluation Technology of Power Supply Enterprise Organizations Matching Company Strategy" (SGZB0000ZGWT2100881).

\section{REFERENCES}

[1] Huang, X., He, M., Wang, S., (2021) Construction of a Model for the Impact of New Electric Power Technologies on Enterprise Organization. Operation and Management., 2:89-92.

[2] Yin, X., (2020) A Humble Opinion on the Change of Corporate Organizational Structure in the Internet era. Business Economics Research., 24:107-110.

[3] Fan, K., (2020) Organizational Reform and Remodeling in the Digital Age. Chinese and Foreign Corporate Culture., 11:1-2.

[4] Zhang, X., Zhang, Z., (2020) Contemporary Enterprise Organization Development (OD)Strategy, Role and Operation System. Chinese Personnel Science., 10: 22-39.

[5] Wang, X., (2020) The Reform and Reconstruction of the Types of Corporate Organizations in China. Time Law., 18:71-76. 